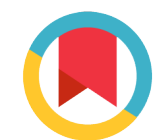

Check for updates

\title{
Transplantation of umbilical cord blood- derived mesenchymal stem cells to treat liver cirrhosis in mice: a comparison of tail and portal vein injection
}

\section{Trinh Van Le ${ }^{1}$, Nam Hai Nguyen ${ }^{1}$, Huy Quang Do1 , Huy Minh Le ${ }^{2}$, Nhung Hai Truong ${ }^{1,3, *}$}

\author{
${ }^{1}$ Stem Cell Institute, University of Science, VNUHCM, Ho Chi Minh city, Vietnam \\ ${ }^{2}$ University of Medicine and Pharmacy Ho Chi Minh City, Ho Chi Minh City, Vietnam \\ ${ }^{3}$ Faculty of Biology-Biotechnology, University of Science, VNUHCM, Ho Chi Minh city, \\ Vietnam
}

\section{*For correspondence:}

thnhung@hcmuns.edu.vn

Competing interests: The authors declare that no competing interests exist.

Received: 17 August 2017 Accepted: 30 August 2017 Published: 10 September 2017

Copyright The Author(s) 2017. This article is published with open access by BioMedPress (BMP).

This article is distributed under the terms of the Creative Commons Attribution License (CC-BY 4.0) which permits any use, distribution, and reproduction in any medium, provided the original author(s) and the source are credited.

\section{Abstract}

Introduction: To date, there have been many studies indicating the positive effects of stem cells on treating liver cirrhosis. In this study, we used umbilical cord blood-derived mesenchymal stem cells (UCB-MSCs) for treatment in a mouse model of liver cirrhosis. Specifically, we determined and compared the effectiveness of two methods of MSC injection (tail vein versus portal vein). Methods: Liver cirrhosis in male Swiss mice (of age approximately 11 weeks or under) was induced by administration of carbon tetrachloride $\left(\mathrm{CCl}_{4} ; 1 \mathrm{ml} / \mathrm{kg}\right)$. One million UCB-MSCs were then transplanted into cirrhotic mice via the portal vein or tail vein. After 21 days, blood samples were collected for measurement of transaminase, bilirubin and albumin. The expression of fibrosis-associated genes, specifically procollagen - alpha 1 and integrin - beta1, were assessed using quantitative RT-PCR. The histopathology of the specimens was also evaluated using hematoxylin/ eosin, Masson trichrome staining, and immunohistochemistry using collagen type 1 and alpha-SMA antibodies. Results: After 21 days, cirrhotic mice treated with UCB-MSCs showed recovery of bilirubin index, increase of liver albumin synthesis, inhibition of fibrosis-related gene expression (e.g. procollagen - alpha 1 and integrin - beta1), and remodeling of liver histology. From comparison of the different routes of transplantation, UCB-portal route was significantly more effective than UCB-tail route at reducing aspartate transaminase (AST) activity and bilirubin index $(P<0.05)$, and inhibiting procollagen - alpha 1 and integrin - beta1 expression $(P<0.05)$. UCB-MSCs from both transfusion routes showed accelerated improvement of liver histopathology. 
Conclusion: Therapeutic strategies using UCB-MSCs have proven to be promising for the treatment of liver cirrhosis. Injection of UCB-MSC via portal vein was more effective than tail vein for cirrhosis treatment.

\section{Keywords}

Liver disease, liver fibrosis, mesenchymal stem cell, stem cell transplantation, umbilical cord blood stem cell

\section{Introduction}

Liver cirrhosis was initially defined by Anthony et al. as "a diffuse process characterized by fibrosis and the conversion of normal liver architecture into structurally abnormal nodules" (Anthony et al., 1978). The unusual structures (i.e. scars or nodules) are formed to replace parenchymal cells which results in the dysfunction of liver and ultimately liver failure. Indeed, liver fibrosis is one of the highest risk factors for liver cancer (Schuppan and Afdhal). According to global statistics, liver disorders have been the predominant cause of over 2 million deaths annually to 2015; approximately 1,200,000 deaths have occurred from chronic liver diseases and liver cirrhosis, and about 800,000 deaths from liver cancer (Wang et al.). Liver cirrhosis can result from a variety of causes, including chronic alcohol abuse, infection with hepatitis viruses (HBV, HCV, etc.), exposure to hepatotoxins, bile duct degeneration, and autoimmune disorders. These factors promote chronic inflammation in the liver, damage-induced cell death (Luedde et al.), accumulation of lipid droplets and hepatic steatosis, reduction of parenchymal cell number, and activation of hepatic stellate cells (HSCs). The activated HSCs can transform into myofibroblasts, causing an increase in cell number. Activation of HSCs is the main reason for the mass production of the extracellular matrix (ECM) (Geerts et al., 1991; Lee et al., 2015). It is the accumulation of ECM that causes scar structures which eventually advance into liver cirrhosis.

Besides eliminating the causes of liver injury, therapies for liver cirrhosis have focused on inhibiting cirrhosis progression, relieving symptoms, and regenerating liver tissue. These attempts have included anti-inflammation and anti-oxidation therapies. Moreover therapies have concentrated on activation/ protection of hepatocytes and inhibition of HSC activation, along with the simultaneous dissolving of scar tissue and replacement of damaged hepatocytes or liver tissue using cell transplantation (Bataller et al., 2005). 
Recently, stem cell therapy have proven to be a promising strategy to treat liver cirrhosis (Eom et al., 2015; Forbes and Newsome, 2012; Guo et al., 2016). The main advantages of stem cell therapies are replacement of damaged hepatocytes by induction of stem cell differentiation into functional cells (SiTayeb et al., 2010; Touboul et al., 2016; Xue et al., 2016) and inhibition of inflammation via immune modulation (Gao et al., 2016; Nauta and Fibbe, 2007). Stem cells also enhance hepatocyte function by releasing growth factors (Fitzpatrick et al., 2015; Zhang and Wang), inhibiting HSC activation and releasing matrix metalloproteinases (MMPs) to dissolve scar tissue (Aki et al., 2015; Amer et al., 2011).

To date, there have been a large number of clinical trials using stem cells to treat liver cirrhosis (Shiota and Itaba, 2016). These studies have exploited various types of stem cells, including mesenchymal stem cells (MSCs), hematopoietic stem cells, and liver progenitor cells. Stem cells have been tested at various doses and administered through various routes. The route of stem cell transplantation can affect not only stem cell homing but also therapeutic efficiency (Kurtz, 2008). In liver disease treatment, Zhong et al. (2013) showed that the magnetic resonance imaging (MRI) signal of labeled MSCs after infusion via portal vein was more effective for cell migration into liver than caudal vein (Zhong et al., 2013).

In the study herein, we investigate two methods of MSC injection to discern the optimal route for administering MSCs. In our study, we evaluate umbilical cord blood derived MSCs (UCB-MSCs) due to their availability, potential for proliferation and differentiation, and efficiency for treating liver disease (Pham et al., 2014; Xue et al., 2015). In a mouse model of liver fibrosis, we compare the efficacy of two methods to deliver UCB-MSCs: caudal (tail) or portal vein.

\section{Materials-Methods}

The study approved by our Institutional Ethics Committee of Laboratory of Stem Cell Research and Application, University of Science, VNU-HCM, Vietnam.

\section{Mouse models}

A mouse model of liver cirrhosis were generated according to previous protocols (Truong et al., 2014). In brief, 6-week old male Swiss mice were treated with carbon tetrachloride $\left(\mathrm{CCl}_{4}\right)$ (UniChem, China) dissolved in olive oil $(3: 7 \mathrm{v} / \mathrm{v})$ at a dose of $1 \mathrm{ml} / \mathrm{kg}$ three times per week for a total of 11 weeks. After 11 weeks, mice were divided into 5 groups (with $n=5$ per group). The 5 treatment groups included: untreated (no injection), placebo-tail (PBS injected into the tail vein), placebo-portal (PBS injected into the portal vein), UCB-tail (UCB-MSCs injected 
into the tail vein), and UCB-portal (UCB-MSCs injected into the portal vein). Additionally, there was a control group (healthy mice).

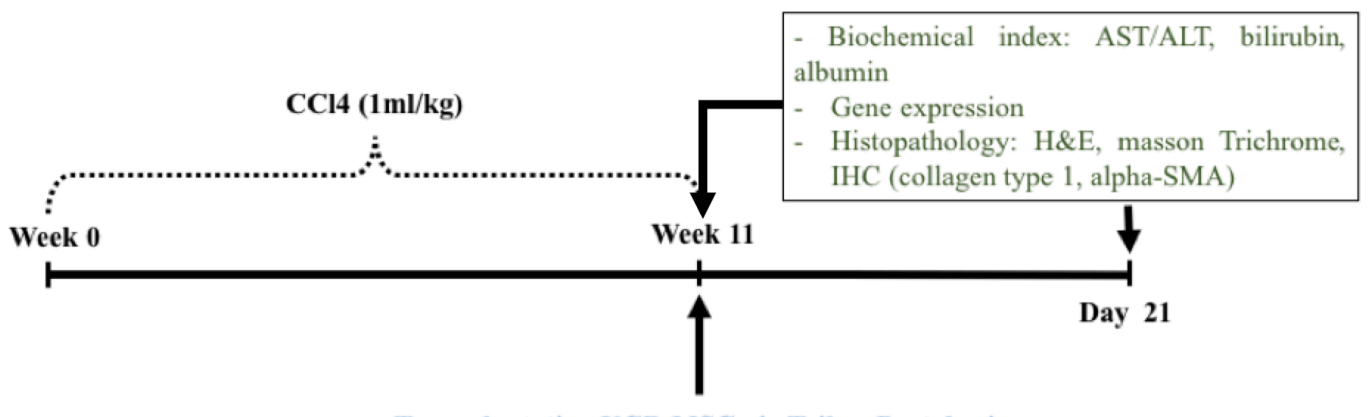

Transplantation UCB-MSC via Tail or Portal vein

Figure 1. Flow chart of the study design.

\section{Cell line}

UCB-MSC cell line was provided by our institute (Institute of Stem Cell, University of Science, Ho Chi Minh City). The cell line was harvested and established using a previously published protocol (Pham et al., 2014). UCBMSCs were thawed and cultured in medium containing DMEM/F12, 10\% FBS, $1 \%$ antibiotic (Sigma-Aldrich, Louis St, $\mathrm{MO}$ ) at $37^{\circ} \mathrm{C}, 5 \% \mathrm{CO}_{2}$. Cell surface markers were determined by flow cytometry using anti-CD14, anti-CD24, antiCD45, anti-CD90, anti-CD166, and anti-CD44 antibodies, either conjugated with FITC or PE (BD Biosciences, San Jose, CA).

\section{Stem cell transplantation}

Stem cells at the 6th passage were detached by trypsin/EDTA, 0.25\% (SigmaAldrich, St. Louis, MO) and filtered through a $70 \mu \mathrm{m}$ cell strainer to harvest single cells for infusion. MSCs $\left(1 \times 10^{6}\right)$ were resuspended in 150 ul phosphate buffer saline (PBS) and then injected via portal or tail vein into mice with liver fibrosis. For stem cell delivery via tail vein, insulin syringes (BD Biosciences) and restraining tubes were used during the administration process. For portal vein injection, mice were anesthetized with ketamine/xylazine prior to injection (Fig. 1).

\section{Biochemical evaluation}

Peripheral blood was obtained to harvest plasma. Enzyme activity of aspartate transaminase (AST) and alanine transaminase (ALT) were evaluated using AST/ ALT kit (Diagnosticum Inc., Hungary). The concentrations of bilirubin and albumin were assayed with QuantiChrom ${ }^{\mathrm{TM}}$ Bilirubin Assay Kit (BioAssay 
Systems, Hayward, CA) and QuantiChrom ${ }^{\mathrm{TM}}$ BCG Albumin Assay Kit (BioAssay Systems), respectively, and according to the manufacturer's instructions.

\section{Fibrosis-associated gene expression}

Small amounts of liver tissue were obtained by liver biopsy for total RNA extraction using Easy-BLUETM Total RNA Extraction Kit (iNtrON Biotechnology, South Korea) according to manufacturer's instructions. Quantitative RT-PCR reactions were carried out using Brilliant II qRT-PCR Master Mix Kit, 1-Step (Agilent, Santa Clara, CA) with procollagen $\alpha 1$ primers (forward: 5'CCTGGACGCCATCAAGGTCTAC-3';reverse:5'-CAAGTTCCGGTGTGACTCG-3'), integrin beta-1 primers (forward: 5'-GCCAGGGCTGGTTATACAGA-3'; reverse: 5'-TCACAATGGCACACAGGTTT-3'), and housekeeping gene GAPDH ( forward: $5^{\prime}$ - AAGTTGTCATGGATGACC - 3 ' ; reverse: 5' ATCACCATCTTCCAGGAGC-3'). The $C t$ values were analyzed using the Livak's method.

\section{Histology}

Liver tissue samples were fixed in $4 \%$ paraformaldehyde solution (Sigma-Aldrich) for at least 24 hours. Fixed samples were embedded in paraffin, sectioned into $5 \mu \mathrm{m}$-thick slices and stained with Hematoxylin/Eosin (Sigma-Aldrich) and Trichrome (Sigma-Aldrich), according to previous protocols (Truong et al., 2016). Immunohistochemistry of the sections was also done according to previous protocols (Truong et al., 2016). In brief, slides were deparaffinized/rehydrated, blocked with blocking serum buffer, with two washes after each step. Then, slides were stained with anti-SMA-alpha antibody (Santa Cruz Biotechnology, Inc., Dallas, TX) and anti-collagen type 1 antibody (Santa Cruz Biotechnology). ACE kit (Sigma-Aldrich) was used as the source of substrate to observe immunocomplexes.

\section{Statistical analysis}

All data were analyzed by Student's t-test using Prism 6.0 (GraphPad Software, Inc., La Jolla, CA) and described as mean \pm SD. Differences were considered statistically significant when p-value $\leq 0.05$.

\section{Results}

Thawed UCB-MSCs exhibited homogeneous morphology with spindle-like shape and showed robust proliferation (Fig. 2A-C). Moreover, flow cytometry analysis of cell surface markers showed that the cells were negative for CD14, CD34, and CD45, but positive for CD90, CD166, and CD44 (Fig. 2). Observation of the thawed cells showed they maintained proliferation and retained their stem-cell properties (Pham et al., 2014). 


\section{UCB-MSCs improve the index of liver injury/function serum markers}

UCB-MSCs contributed to the improvement of bilirubin and albumin levels in mice bearing liver fibrosis. Untreated liver-fibrosis bearing mice showed acute liver damage (Table 2), as indicated by high activity of AST $(240.60 \pm 16.87 \mathrm{U} / \mathrm{L})$, ALT $(411.9 \pm 81 \mathrm{U} / \mathrm{L})$. The increase of bilirubin $(0.26 \pm 0.02 \mathrm{mg} / \mathrm{dL})$ and decrease of albumin $(1.73 \pm 0.0417 \mathrm{mg} / \mathrm{dL})$ reflects liver dysfunction in these untreated mice. For the treatment groups, after 21 days of injection the PBS-treated (placebo) group and UCB-MSC treated groups showed a reduction of AST/ALT index. However, the UCB-MSC treated mice showed a significantly improved level of bilirubin index and albumin, compared to the placebo group $(p<0.05)$ (Fig. 3).
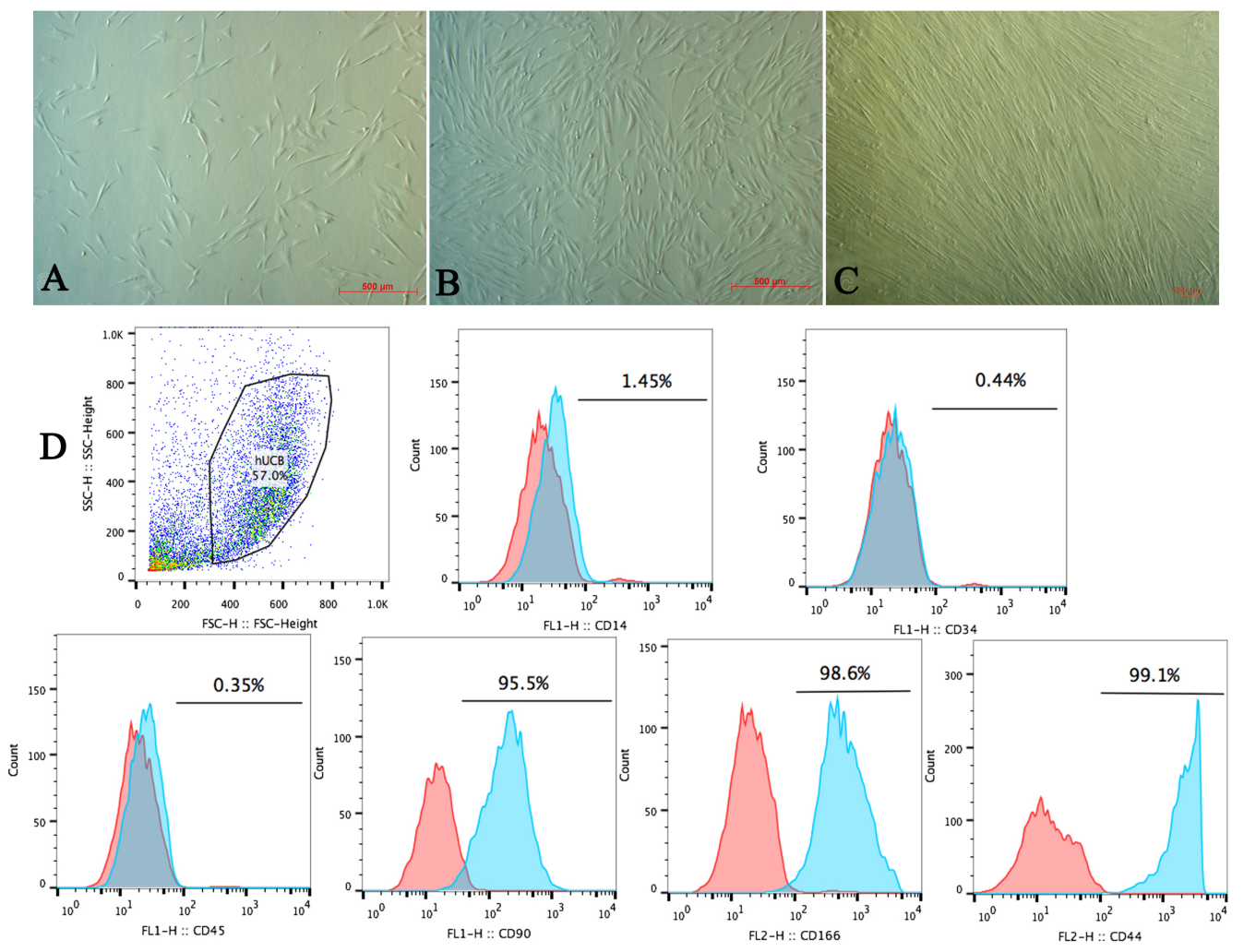

Figure 2. UCB-MSC after thawing. Morphology and surface marker expression of UCB-MSC. (A) UB-MSC after 3 days of thawing; (B-C) UCB-MSC proliferation at $50 \%$ and more than $90 \%$ confluency (respectively); (D) MSC surface markers analysis.

As for the comparison of portal and tail vein route, the portal vein group showed greater efficacy in terms of biochemical index recovery than the tail vein group. The UCB-portal group showed a significantly greater reduction of AST $(69.5 \pm 18.15 \mathrm{U} / \mathrm{L})$ and bilirubin index $(0.104 \pm 0.0082)$, when compared to UCBtail group (127.09 $\pm 35.764 \mathrm{U} / \mathrm{L}$ and $0.2574 \pm 0.04797$, respectively; $p<0.05$ ).

\section{Expression of integrin beta 1 and procollagen $\alpha 1$ genes are reduced in UCB-MSC-treated group}


With respect to gene expression, untreated mice showed an overexpression of integrin beta $1(\sim 1,223,430$-fold greater than healthy mice) and of procollagen $\alpha 1$ expression ( $250-$ fold). These results imply that extracellular matrix and collagen are being overproduced in the liver tissue. After 21 days of UCB-MSC infusion, the expression of integrin beta 1 in UCB-tail and UCB-portal groups were equivalent to healthy mice (expression normalization group); however, the placebo group showed upregulation compared to the healthy mice ( 620-fold in the placebo-portal and 7,350-fold in the placebo-tail groups) (Fig. 4).
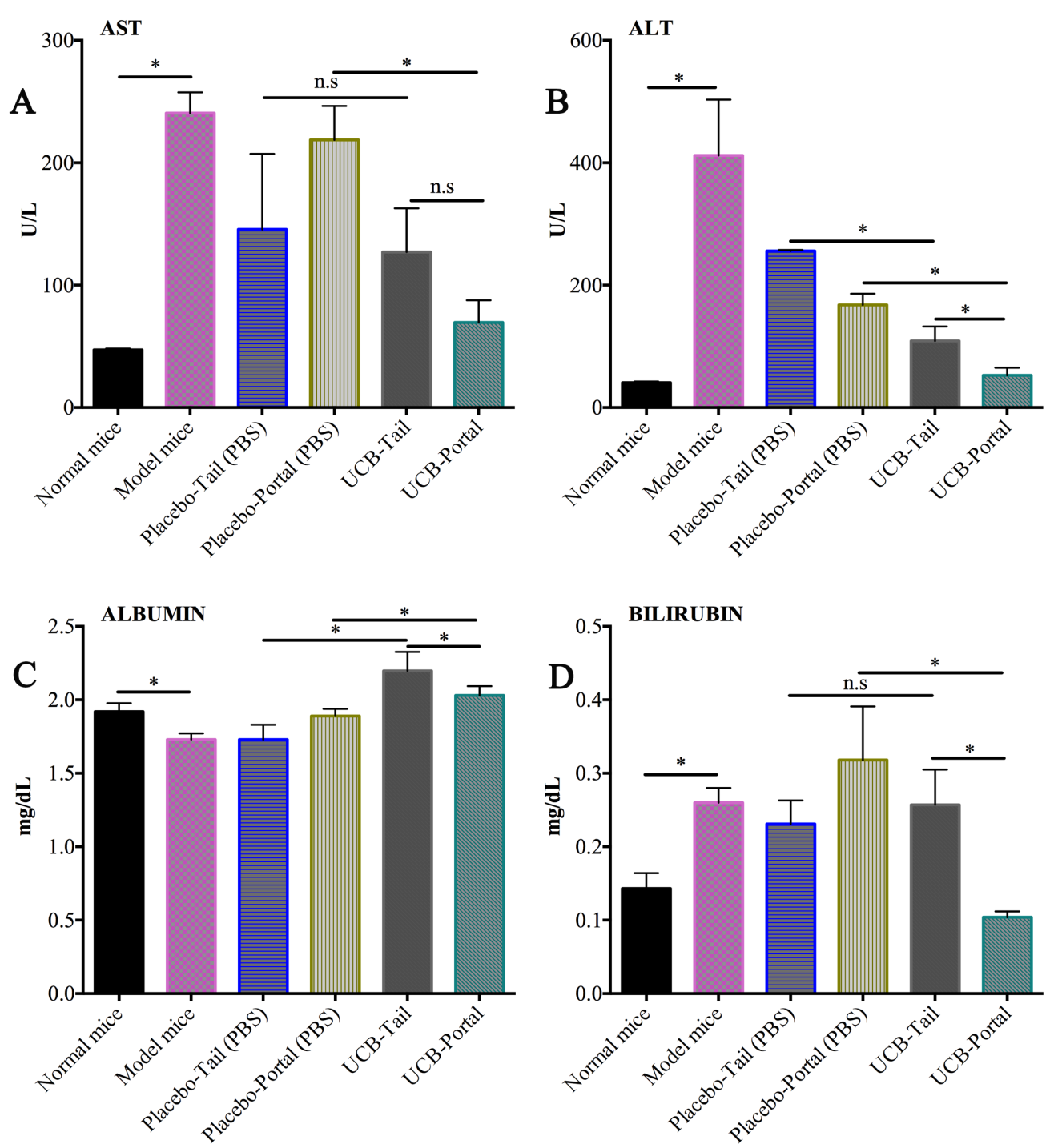

Figure 3. The concentration of liver injury/function serum marker in treated and placebo group. (A) and (B) The level of ast and alt (liver injury serum marker) at day $21^{\text {th }}$ after stem cell transfution; (C) and (D) The level of bilirubin and albumin (liver function serum marker) in the groups at day $21^{\text {th }}$ after treatment stem cell transfusion. 

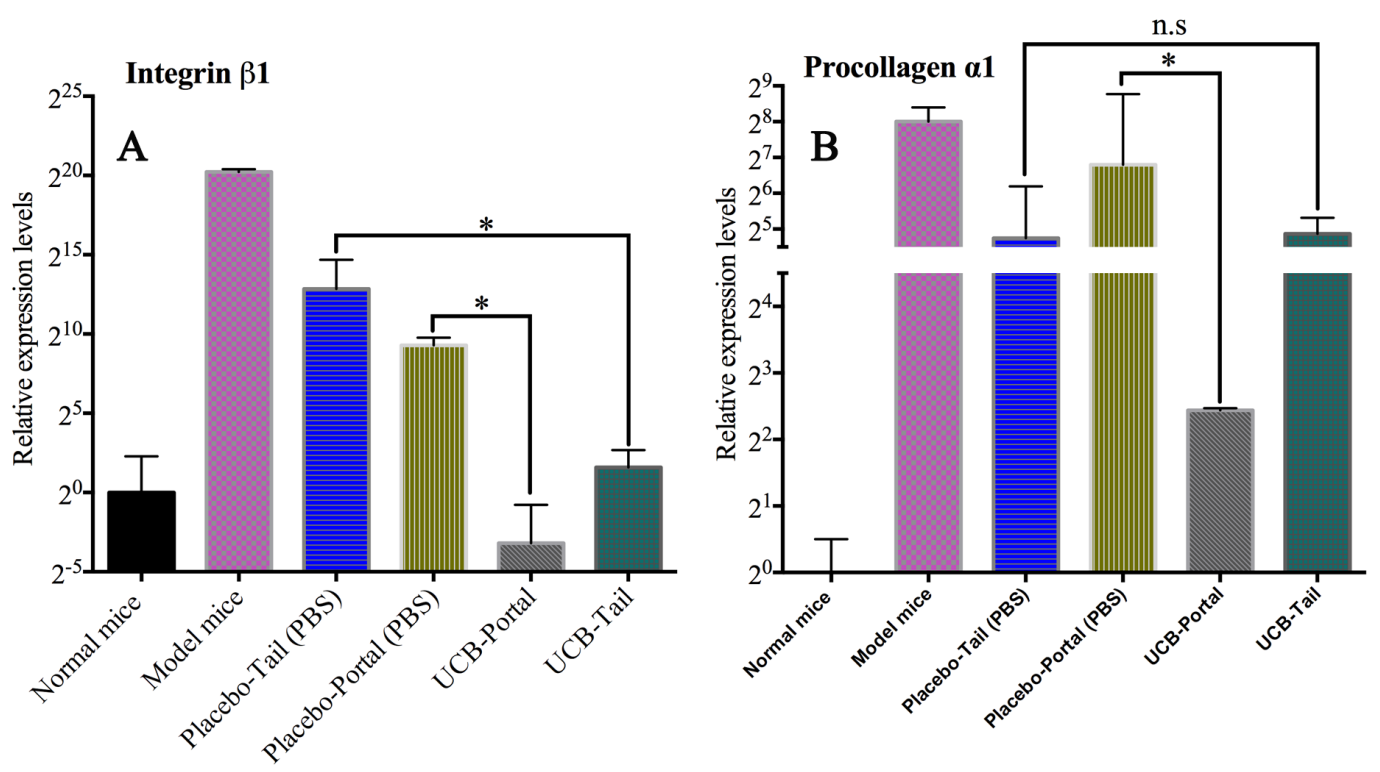

Figure 4. The comparison of integrin beta 1 and procollagen $\alpha 1$ gene expression in the groups. (A) The expression of integrin beta 1 expression in the experiment groups; (B) The expression of procollagen $\alpha 1$ expression in the experiment groups. (Student T-test P-value $=0.05$, * significant difference, n.s: nonsignificant difference).

\section{UCB-MSC transfusion facilitates histopathology recovery in mice bearing liver fibrosis}

From results of H\&E staining, our mouse model of liver cirrhosis exhibited abnormal liver structure and histology, loss of parenchymal cells, increase of white blood cell infiltration into perivascular tissues, hepatocyte death, and hepatocyte steatosis (Fig. $5 \mathrm{C}$ ). There were many myofibroblasts ( $\alpha$-SMA positive cells) observed in the liver tissues of cirrhotic mice (Fig. 6).

Trichrome staining also showed collagen fibers in the liver (fig. 4D). Indeed, liver tissues of the placebo (PBS) group shared similarities with the untreated mouse group (Fig. 5E-H). On the contrary, stem cell treated groups showed an improvement in liver histopathology (Fig. 5I-L). Specifically, UCB-MSC-treated groups showed a decrease of white blood cell infiltration and reduction of hepatocyte steatosis. Furthermore, the trichrome staining showed a decomposition of scar tissues and, notably, diminishment of myofibroblast cell number $(\alpha-S M A+$ cells) and collagen type 1 positive cells in the treated groups (Fig. 6I-L). There was no significant difference between tail vein versus portal vein route of administration in terms of histological structure, inflammation, steatosis, or scar tissue formation. 


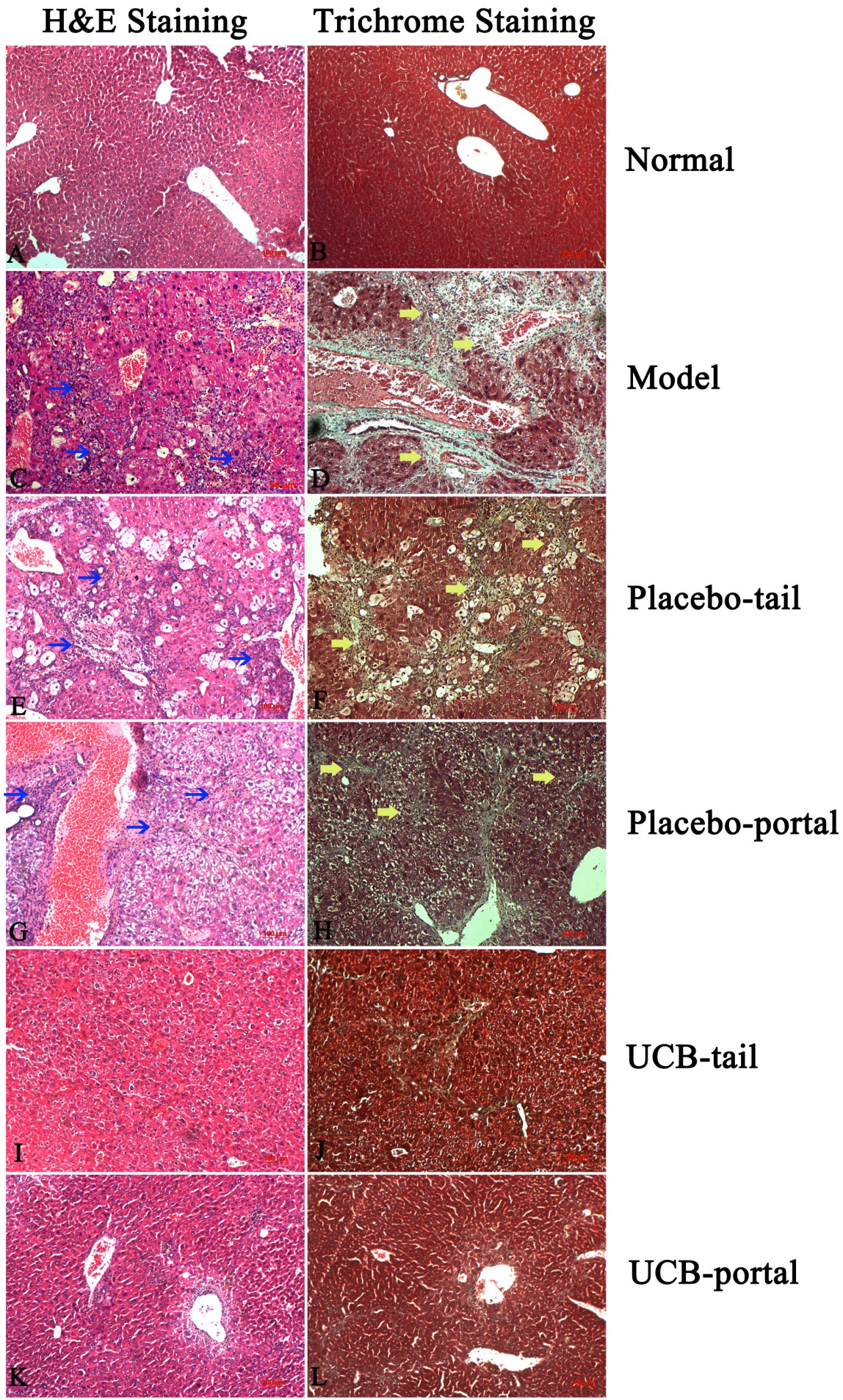

Figure 5. H\&E and Trichrome staining after 21 days of treatment. (A) and (B) Healthy mice; $(\mathbf{C})$ and $(\mathbf{D})$ Model mice; $(\mathbf{E})$ and $(\mathbf{F})$ Placebo-tail group; $(\mathbf{G})$ and $(\mathbf{H})$ Placebo-portal group; (I) and (J) UCB-tail group; (K) and (L) UCB-portal group (blue arrows indicate high infiltration of immune cells, and yellow arrows indicate area of collagen stained with Trichrome dye). 


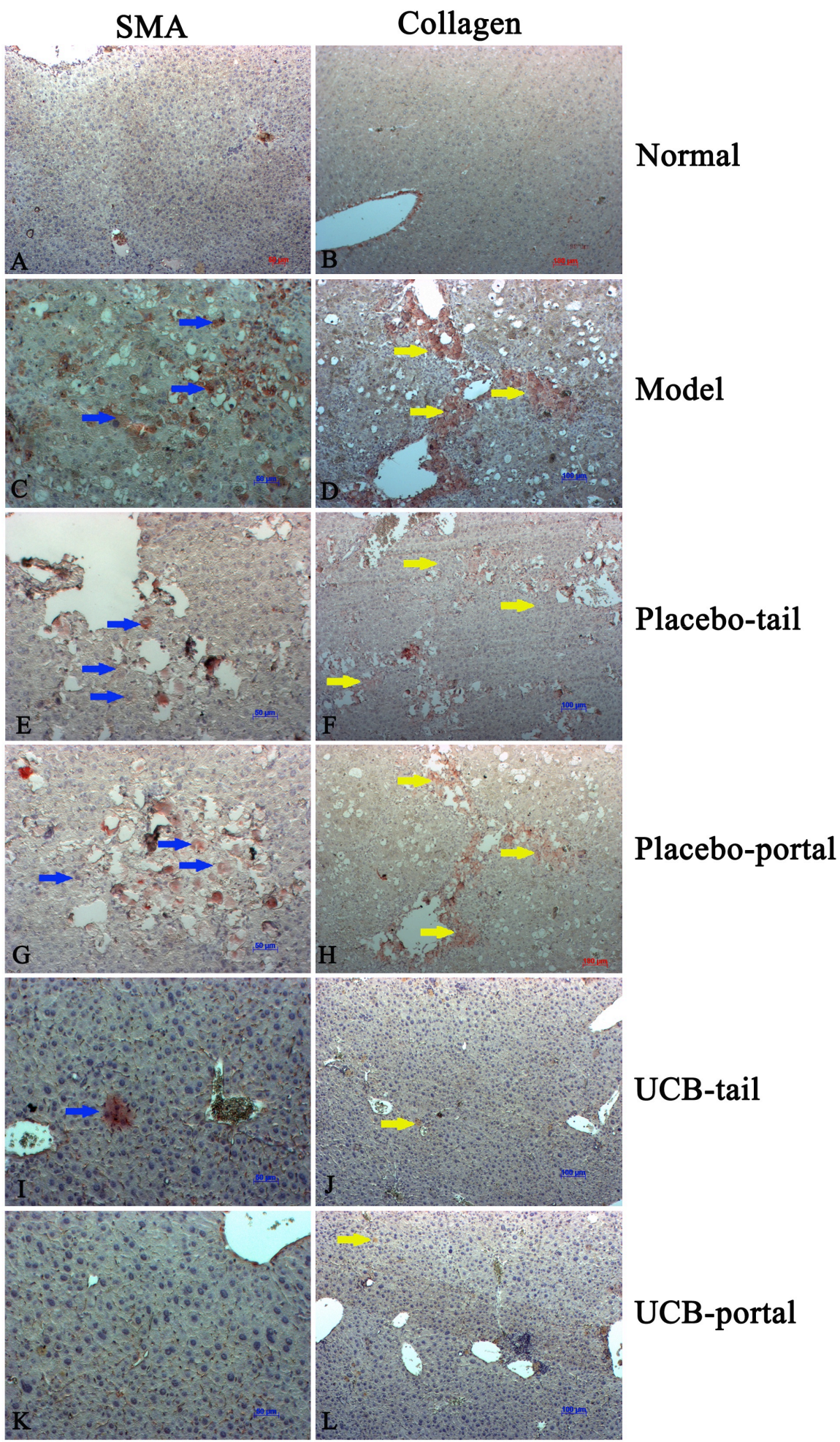

Figure 6. Immunohistochemistry with anti-SMA alpha and anti-collagen type 1. (A) and (B) Healthy mice; (C) and (D) Model mice; (E) and (F) Placebo-tail group; (G) and (H) Placebo-portal group; (I) and (J) UCB-tail group; (K) and (L) UCB-portal group (blue arrows indicate the SMA-alpha-positive cells, yellow arrows indicate the areas of collagen type 1 expression. 


\section{Discussion}

In this study, after 21 days of ceasing $\mathrm{CCl} 4$, both placebo-treated and untreated cirrhotic mice showed reduced liver damage as indicated by a decrease of AST/ ALT index, recovery of histology, and reduction of fibrosis-related gene expression. Presumably, the liver of these mice were capable of selfregeneration. The cause of the self-regeneration has been explained by the ceasing of $\mathrm{CCl}_{4}$ administration during the 21 days of treatment. Other studies have shown similar results to our study (Carvalho et al., 2008; Kuo et al., 2008). However, our study uniquely demonstrates that stem cell treatment in cirrhotic mice was better for restoring liver function and histology (significantly better than placebo treatment). The effects of stem cell treatment in our mouse model of liver cirrhosis may be attributed to stem cell immunomodulation, stem cell homing and differentiation, and secreted cytokines (Berardis et al., 2015).

In terms of stem cell therapy for liver cirrhosis, there are several routes for stem cell infusion; these include peripheral vein, portal vein, intrahepatic, and intrasplenic routes. The safest routes for stem cell injection is peripheral vein (tail vein of mice), and the closest to liver (portal vein). The route of stem cell administration affects stem cell resting and "homing" in organs or tissues following transplantation. The various routes result in different cell distribution, number, action, and efficacy of stem cell in an organism.

In this study, we observed that AST/ALT/bilirubin/albumin levels in the UCB-MSC treated groups were significantly improved compared to the placebo group. The results also showed that stem cell injection via portal vein was significantly better than tail vein. This was reflected by the significant improvement in liver injury/ function index (ALT/bilirubin/albumin levels) induced after portal vein (UCBportal) injection compared to tail vein (UCB-tail) injection. Similar to biochemical index, it was observed that expression of fibrosis-related genes changed positively in the MSC treated groups. Moreover, the portal vein group showed the greatest inhibition of procollagen $\alpha 1$ and integrin beta 1 expression (more efficient than the tail vein group).

Indeed, it has been reported that the route of stem cell administration affects stem cell resting and "homing" in organs/tissues. Different routes can result in different cell distribution, number, action, and efficacy of stem cells in an organism. Since the portal vein is the closest route to the liver, most of the cells should localize in the liver, whereas most cells via tail vein injection will travel to many sites in the body. The results of H\&E, trichrome, and immunohistochemistry staining revealed that UCB-MSC treatment promoted a positive change in histopathology, reduction of collagen fiber, and inhibition of hepatic stellate cells in the liver tissue. Moreover, down-regulation of $\alpha$-SMA cells reflect a decrease of myofibroblasts in the liver (Hinz, 2007).

Therefore, our study results are in accordance to those of Yoon Ok Jang et al. (Jang et al., 2014), Sakaida, Terai (Sakaida et al., 2004), and Krizhanovsky, et al. 
(Krizhanovsky et al., 2008). Moreover, paracrine effects of MSCs may play a significant role in reducing fibrosis in cirrhotic mice. In our study, the two stem cell treated groups (portal vein and tail vein groups) showed no significant difference in terms of histological evaluation. Similar to our study, recent studies in rats have also found that MSC infusion via portal vein is more beneficial than caudal vein with regards to MSC "homing" and improvement of liver function (Zheng et al., 2015). In a study by Sun et al. (2014) which compared four different routes of bone marrow (BM)-MSC transplantation in a rat model, portal vein administration was found to have greater impact on stem cell "homing" than the other routes (Sun et al., 2014). Furthermore, portal vein was the best route for transplanting MSCs and improved rat liver function compared to hepatic artery, peripheral vein or intrahepatic routes (Sang et al., 2016).

Fundamentally, the function of the portal vein is to serve as the main blood vessel which brings blood from the intestines directly to liver sinusoid network such that portal vein injection promotes "cell homing" to liver tissue more than other routes (Fan et al., 2001; Zhang et al., 1994; Zhong et al., 2013). For that reason, and from our study results, the portal vein should be regarded as a priority route for UCB-MSC treatment of liver cirrhosis, with careful considerations to eliminate the risk of bleeding and damage to the recipient organ (Paul et al., 2009).

\section{Conclusion}

Transplantation of UCB-MSCs is a promising method for treating liver cirrhosis. In this study, UCB-MSC transplantation via portal vein, as compared to tail vein, was significantly more efficient at reducing liver injury, improving liver function and inhibiting expression of fibrosis-related genes. Thus, portal vein administration may be an optimal route for UCB-MSC administration in the treatment of liver cirrhosis.

\section{Acknowledgment}

This study was funded by Vietnam National University, Ho Chi Minh City under grant number B2012-18-07TD. We highly appreciate Dr. Phuc Van Pham who established UCBMSC cell line. 


\section{Progress in \\ S TE M C E L L}

ISSN: 2199-4633 www.cellstemcell.org

\section{Abbreviations}

UCB-MSCs: Umbilical cord blood derived mesenchymal stem cells

$\mathrm{CCl}_{4}$ : Carbon Tetrachloride

ALB: Albumin

AST: Aspartate Amino Transferase

ALT: Alanine Amino Transferase

qRT-PCR: Quantitative reverse transcription polymerase chain reaction

HBV: Hepatitis B Virus

HCV: Hepatitis C Virus

HSCs: Hepatic Stellate Cells

ECM: Extracellular Matrix

MMPs: Matrix Metalloproteinase

GADPH: Glyceraldehyde 3-phosphate Dehydrogenase

SMA-alpha: Smooth Muscle Actin alpha

BM-MSC: Bone marrow - Mesenchymal Stem cell

\section{Author Contribution}

Trinh Van Le conducted experiments, acquisition of data and compose the first manuscript. Nam Hai Nguyen and Huy Quang Do established the mouse model, acquisition data of liver function, gene-expression. Huy Minh Le made substantial contributions to analyze the histology change. Nhung Hai Truong made substantial contributions to conception and design, data analysis and interpretation of data. Being corresponding author, Truong Hai Nhung give final approval of the manuscript to be submitted and any revised version. All authors read and approved this manuscript before it was submitted.

\section{References}

Aki, S.Z., Suyani, E., Cengiz, M., Ozenirler, S., Elbeg, S., Pasaoglu, H., and Sucak, G.T. (2015). Association between Plasma Endothelin-1, Transforming Growth Factor-beta, Fibroblast Growth Factor, and Nitric Oxide Levels and Liver Injury in Hematopoietic Stem Cell Transplantation Recipients with Persistent Iron Overload after Transplantation. Biology of blood and marrow transplantation : journal of the American Society for Blood and Marrow Transplantation 21, 948-953. https://doi.org/10.1016/ j.bbmt.2015.02.002

Amer, M.E., El-Sayed, S.Z., El-Kheir, W.A., Gabr, H., Gomaa, A.A., El-Noomani, N., and Hegazy, M. (2011). Clinical and laboratory evaluation of patients with end-stage liver cell failure injected with bone marrow-derived hepatocyte-like cells. European journal of gastroenterology \& hepatology 23, 936-941. https://doi.org/10.1097/MEG. 0b013e3283488b00 


\section{Progress in \\ STEM C E L L}

ISSN: 2199-4633 www.cellstemcell.org

Anthony, P.P., Ishak, K.G., Nayak, N.C., Poulsen, H.E., Scheuer, P.J., and Sobin, L.H. (1978). The morphology of cirrhosis. Recommendations on definition, nomenclature, and classification by a working group sponsored by the World Health Organization. Journal of clinical pathology 31, 395-414. https://doi.org/10.1136/jcp.31.5.395

Bataller, R., xF, and Brenner, D.A. (2005). Liver fibrosis. The Journal of clinical investigation 115, 209-218. https://doi.org/10.1172/JCl24282

Berardis, S., Dwisthi Sattwika, P., Najimi, M., and Sokal, E.M. (2015). Use of mesenchymal stem cells to treat liver fibrosis: Current situation and future prospects. World Journal of Gastroenterology : WJG 21, 742-758. https://doi.org/10.3748/wjg.v21.i3.742

Carvalho, A.B., Quintanilha, L.F., Dias, J.V., Paredes, B.D., Mannheimer, E.G., Carvalho, F.G., Asensi, K.D., Gutfilen, B., Fonseca, L.M.B., Resende, C.M.C., et al. (2008). Bone Marrow Multipotent Mesenchymal Stromal Cells Do Not Reduce Fibrosis or Improve Function in a Rat Model of Severe Chronic Liver Injury. STEM CELLS 26, 1307-1314. https://doi.org/10.1634/stemcells.2007-0941

Eom, Y.W., Kim, G., and Baik, S.K. (2015). Mesenchymal stem cell therapy for cirrhosis: Present and future perspectives. World journal of gastroenterology 21, 10253-10261. https://doi.org/10.3748/wjg.v21.i36.10253

Fan, T.-X., Hisha, H., Jin, T.-N., Yu, C.-Z., Lian, Z.-X., Guo, S.-B., Cui, Y.-Z., Feng, B., Yang, G.-X., Li, Q., et al. (2001). Successful Allogeneic Bone Marrow Transplantation (BMT) by Injection of Bone Marrow Cells via Portal Vein: Stromal Cells as BMT-Facilitating Cells. STEM CELLS 19, 144-150. https://doi.org/10.1634/stemcells.19-2-144

Fitzpatrick, E., Wu, Y., Dhadda, P., Hughes, R.D., Mitry, R.R., Qin, H., Lehec, S.C., Heaton, N.D., and Dhawan, A. (2015). Coculture with mesenchymal stem cells results in improved viability and function of human hepatocytes. Cell Transplant 24, 73-83. https://doi.org/10.3727/096368913X674080

Forbes, S.J., and Newsome, P.N. (2012). New horizons for stem cell therapy in liver disease. J Hepatol 56, 496-499. https://doi.org/10.1016/j.jhep.2011.06.022

Gao, F., Chiu, S.M., Motan, D.A.L., Zhang, Z., Chen, L., Ji, H.L., Tse, H.F., Fu, Q.L., and Lian, Q. (2016). Mesenchymal stem cells and immunomodulation: current status and future prospects. Cell Death Dis 7, e2062. https://doi.org/10.1038/cddis.2015.327

Geerts, A., Lazou, J.M., De Bleser, P., and Wisse, E. (1991). Tissue distribution, quantitation and proliferation kinetics of fat-storing cells in carbon tetrachloride-injured rat liver. Hepatology (Baltimore, Md) 13, 1193-1202. https://doi.org/ 10.1016/0270-9139(91)92491-P

Guo, Y., Chen, B., Chen, L.J., Zhang, C.F., and Xiang, C. (2016). Current status and future prospects of mesenchymal stem cell therapy for liver fibrosis. Journal of Zhejiang University Science B 17, 831-841. https://doi.org/10.1631/jzus.B1600101

Hinz, B. (2007). Formation and function of the myofibroblast during tissue repair. The Journal of investigative dermatology 127, 526-537. https://doi.org/10.1038/sj.jid. $\underline{5700613}$

Jang, Y.O., Kim, M.Y., Cho, M.Y., Baik, S.K., Cho, Y.Z., and Kwon, S.O. (2014). Effect of bone marrow-derived mesenchymal stem cells on hepatic fibrosis in a thioacetamideinduced cirrhotic rat model. BMC gastroenterology 14, 198. https://doi.org/10.1186/ s12876-014-0198-6 


\section{Progress in \\ S TE M C E L L}

ISSN: 2199-4633

www.cellstemcell.org

Krizhanovsky, V., Yon, M., Dickins, R.A., Hearn, S., Simon, J., Miething, C., Yee, H., Zender, L., and Lowe, S.W. (2008). Senescence of activated stellate cells limits liver fibrosis. Cell 134, 657-667. https://doi.org/10.1016/j.cell.2008.06.049

Kuo, T.K., Hung, S.P., Chuang, C.H., Chen, C.T., Shih, Y.R., Fang, S.C., Yang, V.W., and Lee, O.K. (2008). Stem cell therapy for liver disease: parameters governing the success of using bone marrow mesenchymal stem cells. Gastroenterology 134, 2111-2121, 2121.e2111-2113. https://doi.org/10.1053/j.gastro.2008.03.015

Kurtz, A. (2008). Mesenchymal Stem Cell Delivery Routes and Fate. International journal of stem cells 1, 1-7. https://doi.org/10.15283/ijsc.2008.1.1.1

Lee, Y.A., Wallace, M.C., and Friedman, S.L. (2015). Pathobiology of liver fibrosis: a translational success story. Gut 64, 830. https://doi.org/10.1136/gutjnl-2014-306842

Luedde, T., Kaplowitz, N., and Schwabe, R.F. Cell Death and Cell Death Responses in Liver Disease: Mechanisms and Clinical Relevance. Gastroenterology 147, 765-783.e764. Schuppan, D., and Afdhal, N.H. Liver cirrhosis. The Lancet 371, 838-851.

Nauta, A.J., and Fibbe, W.E. (2007). Immunomodulatory properties of mesenchymal stromal cells. Blood 110, 3499. https://doi.org/10.1182/blood-2007-02-069716

Paul, A., Ge, Y., Prakash, S., and Shum-Tim, D. (2009). Microencapsulated stem cells for tissue repairing: implications in cell-based myocardial therapy. Regenerative Medicine 4, 733-745. https://doi.org/10.2217/rme.09.43

Pham, P.V., Vu, N.B., Pham, V.M., Truong, N.H., Pham, T.L.-B., Dang, L.T.-T., Nguyen, T.T., Bui, A.N.-T., and Phan, N.K. (2014). Good manufacturing practice-compliant isolation and culture of human umbilical cord blood-derived mesenchymal stem cells. Journal of Translational Medicine 12, 56-56. https://doi.org/10.1186/1479-5876-12-56

Sakaida, I., Terai, S., Yamamoto, N., Aoyama, K., Ishikawa, T., Nishina, H., and Okita, K. (2004). Transplantation of bone marrow cells reduces CCl4-induced liver fibrosis in mice. Hepatology (Baltimore, Md) 40, 1304-1311. https://doi.org/10.1002/hep.20452

Sang, J.F., Shi, X.L., Han, B., Huang, T., Huang, X., Ren, H.Z., and Ding, Y.T. (2016). Intraportal mesenchymal stem cell transplantation prevents acute liver failure through promoting cell proliferation and inhibiting apoptosis. Hepatobiliary \& pancreatic diseases international : HBPD INT 15, 602-611. https://doi.org/10.1016/ S1499-3872(16)60141-8

Shiota, G., and Itaba, N. (2016). Progress in stem cell-based therapy for liver disease. Hepatology Research.

Si-Tayeb, K., Noto, F.K., Nagaoka, M., Li, J., Battle, M.A., Duris, C., North, P.E., Dalton, S., and Duncan, S.A. (2010). Highly efficient generation of human hepatocyte-like cells from induced pluripotent stem cells. Hepatology (Baltimore, Md) 51, 297-305. https:// doi.org/10.1002/hep.23354

Sun, L., Fan, X., Zhang, L., Shi, G., Aili, M., Lu, X., Jiang, T., and Zhang, Y. (2014). Bone mesenchymal stem cell transplantation via four routes for the treatment of acute liver failure in rats. International journal of molecular medicine 34, 987-996. https://doi.org/ 10.3892/ijmm.2014.1890

Touboul, T., Chen, S., To, C.C., Mora-Castilla, S., Sabatini, K., Tukey, R.H., and Laurent, L.C. (2016). Stage-specific regulation of the WNT/beta-catenin pathway enhances differentiation of hESCs into hepatocytes. J Hepatol 64, 1315-1326. https://doi.org/ 10.1016/j.jhep.2016.02.028

Truong, H.N., Nguyen, H.N., Nguyen, T.K.N., Le, M.H., Tran, H.G., Huynh, N., and Nguyen, T.V. (2014). Establishment of a standardized mouse model of hepatic fibrosis 


\section{Progress in \\ S TE M C E L L}

ISSN: 2199-4633

www.cellstemcell.org

for biomedical research. Biomed Res Ther 1, 43-49. https://doi.org/10.7603/ s40730-014-0009-2

Truong, N.H., Nguyen, N.H., Le, T.V., Vu, N.B., Huynh, N., Nguyen, T.V., Le, H.M., Phan, N.K., and Pham, P.V. (2016). Comparison of the Treatment Efficiency of Bone MarrowDerived Mesenchymal Stem Cell Transplantation via Tail and Portal Veins in CCl4Induced Mouse Liver Fibrosis. Stem Cells International 2016, 13. https://doi.org/ $\underline{10.1155 / 2016 / 5720413}$

Wang, H., Naghavi, M., Allen, C., Barber, R.M., Bhutta, Z.A., Carter, A., Casey, D.C., Charlson, F.J., Chen, A.Z., Coates, M.M., et al. Global, regional, and national life expectancy, all-cause mortality, and cause-specific mortality for 249 causes of death, 1980\&\#x2013;2015: a systematic analysis for the Global Burden of Disease Study 2015. The Lancet 388, 1459-1544.

Xue, G., Han, X., Ma, X., Wu, H., Qin, Y., Liu, J., Hu, Y., Hong, Y., and Hou, Y. (2016). Effect of Microenvironment on Differentiation of Human Umbilical Cord Mesenchymal Stem Cells into Hepatocytes In Vitro and In Vivo. BioMed research international 2016, 8916534. Zhang, Z., and Wang, F.-S. Stem cell therapies for liver failure and cirrhosis. Journal of Hepatology 59, 183-185.

Xue, H.L., Zeng, W.Z., Wu, X.L., Jiang, M.D., Zheng, S.M., Zhang, Y., and Li, H.Y. (2015). Clinical therapeutic effects of human umbilical cord-derived mesenchymal stem cells transplantation in the treatment of end-stage liver disease. Transplantation proceedings 47, 412-418. https://doi.org/10.1016/j.transproceed.2014.10.048

Zhang, Y., Yasumizu, R., Sugiura, K., Hashimoto, F., Amoh, Y., Lian, Z., Cherry, Nishio, N., and Ikehara, S. (1994). Fate of allogeneic or syngeneic cells in intravenous or portal vein injection: Possible explanation for the mechanism of tolerance induction by portal vein injection. European Journal of Immunology 24, 1558-1565. https://doi.org/ $\underline{10.1002 / e j i .1830240716}$

Zheng, S., Yang, J., Yang, J., Tang, Y., Shao, Q., Guo, L., and Liu, Q. (2015). Transplantation of umbilical cord mesenchymal stem cells via different routes in rats with acute liver failure. International journal of clinical and experimental pathology 8 , 15854-15862.

Zhong, Y., Tang, Z., Xu, R., Lin, N., Deng, M., Fang, H., Lin, J., Zhu, K., Liu, Y., and Kang, Z. (2013). Effect of transplantation route on stem cell migration to fibrotic liver of rats via cellular magnetic resonance imaging. Cytotherapy 15, 1266-1274. https://doi.org/ 10.1016/j.jcyt.2013.05.023 